\title{
Pharmacogenomics Biomarker Domain
}

National Cancer Institute

\section{Source}

National Cancer Institute. Pharmacogenomics Biomarker Domain. NCI Thesaurus. Code C106552.

A special purpose domain and reference dataset that associates observed genetic mutations with medical conclusions (e.g. disease diagnosis, drug resistance). 